\title{
Procalcitonin Impairs Liver Cell Viability and Function In Vitro: A Potential New Mechanism of Liver Dysfunction and Failure during Sepsis?
}

\author{
Martin Sauer, ${ }^{1,2}$ Sandra Doß, ${ }^{2}$ Johannes Ehler, ${ }^{1}$ \\ Thomas Mencke, ${ }^{1}$ and Nana-Maria Wagner ${ }^{1}$ \\ ${ }^{1}$ Clinic for Anesthesiology and Intensive Care Medicine, University Hospital Rostock, Rostock, Germany \\ ${ }^{2}$ Fraunhofer Institute for Cell Therapy and Immunology, EXIM, Rostock, Germany \\ Correspondence should be addressed to Martin Sauer; martin.sauer@uni-rostock.de
}

Received 12 November 2016; Revised 5 January 2017; Accepted 10 January 2017; Published 1 February 2017

Academic Editor: Anastasia Kotanidou

Copyright (c) 2017 Martin Sauer et al. This is an open access article distributed under the Creative Commons Attribution License, which permits unrestricted use, distribution, and reproduction in any medium, provided the original work is properly cited.

Purpose. Liver dysfunction and failure are severe complications of sepsis and result in poor outcome and increased mortality. The underlying pathologic mechanisms of hepatocyte dysfunction and necrosis during sepsis are only incompletely understood. Here, we investigated whether procalcitonin, a biomarker of sepsis, modulates liver cell function and viability. Materials and Methods. Employing a previously characterized and patented biosensor system evaluating hepatocyte toxicity in vitro, human hepatocellular carcinoma cells (HepG2/C3A) were exposed to $0.01-50 \mathrm{ng} / \mathrm{mL}$ procalcitonin for $2 \times 72 \mathrm{~h}$ and evaluated for proliferation, necrosis, metabolic activity, cellular integrity, microalbumin synthesis, and detoxification capacity. Acetaminophen served as positive control. For further standardization, procalcitonin effects were confirmed in a cellular toxicology assay panel employing L929 fibroblasts. Data were analyzed using ANOVA/Tukey's test. Results. Already at concentrations as low as $0.25 \mathrm{ng} / \mathrm{mL}$, procalcitonin induced HepG2/C3A necrosis $(P<0.05)$ and reduced metabolic activity, cellular integrity, synthesis, and detoxification capacity (all $P<$ 0.001). Comparable effects were obtained employing L929 fibroblasts. Conclusion. We provide evidence for procalcitonin to directly impair function and viability of human hepatocytes and exert general cytotoxicity in vitro. Therapeutical targeting of procalcitonin could thus display a novel approach to reduce incidence of liver dysfunction and failure during sepsis and lower morbidity and mortality of septic patients.

\section{Introduction}

Sepsis is one of the leading causes of death in critically ill patients admitted to intensive care units [1]. High mortality rates are due to the development of multiple organ dysfunction syndrome (MODS) [2]. Hepatic dysfunction is a key component of MODS and liver failure occurs in nearly $19 \%$ of patients with septic shock. Hepatic dysfunction thereby crucially contributes to poor prognosis and outcome [3]. In the pathophysiology of sepsis, the liver modulates several aspects of disease initiation and progression. For example, it clears bacteria and endotoxin from the splanchnic area and tailors host immune responses by secreting inflammatory mediators $[4,5]$. Although impairment of liver cell function is thus one of the most crucial amplifiers of MODS during sepsis, its pathophysiology during sepsis is still incompletely understood [6].

Procalcitonin is considered one of the earliest and most predictive biomarkers for the identification, treatment, and prognosis of septic patients. Procalcitonin is a 116-amino acid precursor protein of calcitonin secreted by endotoxin- or pathogen-activated monocytes $[7,8]$. During the course of bacterial sepsis, further procalcitonin secretion by parenchymal cells of various organs results in a burst of procalcitonin plasma concentrations of up to 100,000 -fold $[7,9,10]$. In animal models, procalcitonin administration to septic hamsters results in doubled lethality rates [11]. Conversely, procalcitonin neutralization during sepsis improves survival in hamsters and pigs $[11,12]$, suggesting procalcitonin itself to play a role in sepsis pathology [13]. In this regard, we have 
recently identified procalcitonin to impair endothelial cell viability and function and thus to potentially contribute to disturbed microcirculation and hypoperfusion during sepsis [14].

In the present study, we aimed to elucidate a potential direct role of procalcitonin in modulating liver cell function. We employed a previously patented [15] and characterized biosensor system [16] investigating the effects of $0.01-$ $50 \mathrm{ng} / \mathrm{mL}$ procalcitonin on vitality, viability, and function of hepatocytes. We further verified results in a standardized toxicology screening assay employing murine fibroblasts to further characterize procalcitonin cytotoxic potency in vitro.

\section{Methods}

2.1. Cell Culture, Cell Proliferation, and Vitality. A human hepatocyte cell line HepG2/C3A was obtained from the American Type Culture Collection (ATCC CRL-10741, WCB 25022009) and cultivated in Dulbecco's modified Eagle's Medium (Dulbecco's DMEM, GIBCO Life Technologies, Eggenstein, Germany), supplemented with $10 \%$ fetal calf serum (PAA Laboratories, Cölbe, Germany), 1\% of glutamine solution (PAA), and $1 \%$ of antibiotics solution (Penicillin G: 10,000 IE/mL/Streptomycin: $10 \mathrm{mg} / \mathrm{mL}$; PAA). For incubation with procalcitonin, 250,000 hepatocytes were seeded per well of a 24-well plate, incubated in $1 \mathrm{~mL}$ medium for $72 \mathrm{~h}$, and exposed to procalcitonin (Sigma-Aldrich, Steinheim am Albuch, Germany) ranging from 0.01 to $50 \mathrm{ng} / \mathrm{mL}$ or phosphate buffered saline (PBS) only serving as vehicle control (negative control). Medium was then removed and replaced by fresh medium supplemented with similar procalcitonin concentrations or PBS. Following $72 \mathrm{~h}$, proliferation and vitality were assessed by trypan blue staining technique and manual cell counts. Exposure to acetaminophen (15.24 mM, Sigma-Aldrich) for two times $72 \mathrm{~h}$ served as positive control [15].

2.2. Cell Viability. Hepatocyte viability was investigated following incubation of cells with 2,3-bis(2-methoxy-4-nitro5-sulfophenyl)-5-[(phenylamino)carbonyl $]-2 \mathrm{H}$-tetrazolium hydroxide (XTT) which is metabolically reduced in viable cells by mitochondrial dehydrogenase to a water-soluble formazan product detectable by absorbance readings [16, 17]. $\mathrm{LDH}$ determination from cell culture medium supernatant was performed according to the optimized standard method of the German Society of Clinical Chemistry (Deutsche Gesellschaft für Klinische Chemie, DGKC). Pyruvate was employed as a substrate and NADH decrease was determined photometrically (Cobas Mira, Roche) [18].

2.3. Hepatocyte Function. For the determination of microalbumin synthesis, hepatocytes were incubated with procalcitonin for two times $72 \mathrm{~h}$ and supernatants were collected, centrifuged, and stored at $-80^{\circ} \mathrm{C}$ pending analysis. Microalbumin was then determined nephelometrically (Immage 800, Beckmann Coulter GmbH, Krefeld, Germany) [19]. Induction of hepatocyte cytochrome 1A2 activity was evaluated by incubation of hepatocytes with 7-ethoxyresorufin
(7-ER), a fluorimetric substrate and suicide inhibitor of cytochrome P450 reflecting the activity of cytochrome 1A2 by ethoxyresorufin-O-deethylase (EROD) activity [20].

2.4. Murine Fibroblasts Toxicology Screen. Murine fibroblasts were grown in Dulbecco's modified Eagle's Medium supplemented with $5 \%$ fetal calf serum, $1 \%$ of glutamine solution (PAA), and $1 \%$ of antibiotics solution according to 9935 ISO Norm. Effects of $0.01-100 \mathrm{ng} / \mathrm{mL}$ procalcitonin on proliferation, vitality, and mitochondrial dehydrogenase were investigated as mentioned above.

2.5. Statistical Analysis. Data was analyzed employing GraphPad Prism Software version 7.01 (GraphPad Prism Software Inc., La Jolla, CA, USA) using One-Way ANOVA followed by Tukey's test for correction of multiple comparisons. The results are expressed as mean and standard deviation (SD). Differences were considered significant at a $P$ value of $\leq 0.05$.

\section{Results}

3.1. Procalcitonin Impairs Hepatocyte Vitality and Viability. Incubation of hepatocytes with procalcitonin ranging from 0.01 to $50 \mathrm{ng} / \mathrm{mL}$ dose dependently inhibited hepatocyte proliferation over the time-course of $72 \mathrm{~h}$ with significant effects starting at $2.5 \mathrm{ng} / \mathrm{mL}(0.55 \pm 0.23$-fold versus ctrl, $P<0.001$; Figure 1(a)). Beginning at low concentrations as $0.25 \mathrm{ng} / \mathrm{mL}$, procalcitonin also affected hepatocyte viability indicated by reduced numbers of trypan blue-negative cells $(0.82 \pm 0.15$-fold versus ctrl, $P<0.05$; Figure $1(b))$. Incubation with procalcitonin at all concentrations employed severely impacted basic cell metabolism $(0.72 \pm 0.23$-fold versus ctrl for $0.01 \mathrm{ng} / \mathrm{mL}, P<0.001$, Figure $1(\mathrm{c}))$ and concentrations starting at $0.25 \mathrm{ng} / \mathrm{mL}$ induced the release of $\mathrm{LDH}$ into cell culture supernatants $(2.04 \pm 0.07$-fold versus control, $P<0.001$, Figure 1(d)). For proliferation, vitality, and metabolism, only high concentrations of procalcitonin (i.e., $50 \mathrm{ng} / \mathrm{mL}$ ) induced comparable loss of cell integrity as acetaminophen. For LDH release, already $2.5 \mathrm{ng} / \mathrm{mL}$ induced comparable effects as acetaminophen employed as positive control.

3.2. Procalcitonin Reduces Hepatocyte Synthesis and Detoxification Potency. Next, we investigated the degree procalcitonin-mediated affection of vitality and viability has implications for hepatocyte albumin synthesis and ethanol clearance. In this regard, all concentrations of procalcitonin employed severely affected microalbumin synthesis with already low concentrations such as $0.01 \mathrm{ng} / \mathrm{mL}$ reducing synthesis capacity to only half of that of control cells $(0.46 \pm 0.14$-fold versus ctrl for $0.01 \mathrm{ng} / \mathrm{mL}, P<0.001$, Figure 2(a)). The activity of the cytochrome P450 1A2 detoxification system was significantly affected at concentrations of $2.5 \mathrm{ng} / \mathrm{mL}(0.79 \pm 0.23$-fold versus ctrl, $P<0.05$; Figure 2(b)).

3.3. Procalcitonin Exerts General Cytotoxicity. Results from analyzing hepatocytes indicating cytotoxic effects of procalcitonin were further verified in a standardized cell-based 


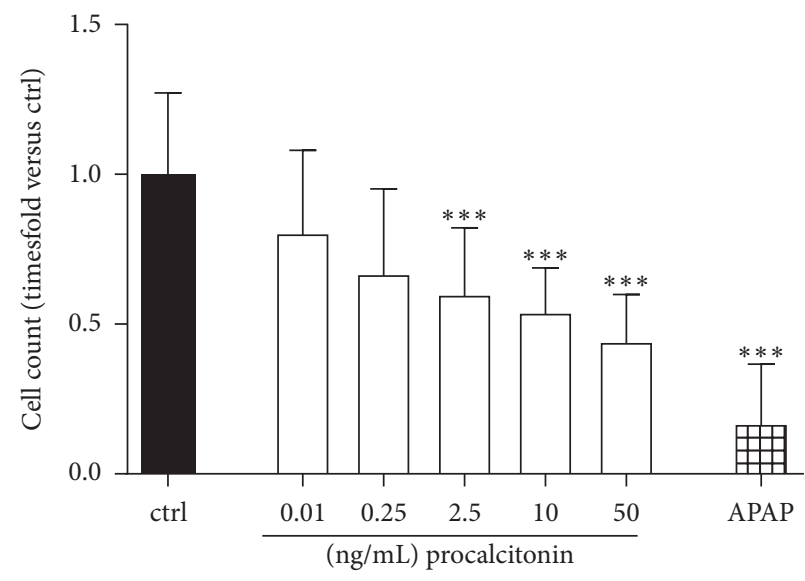

(a)

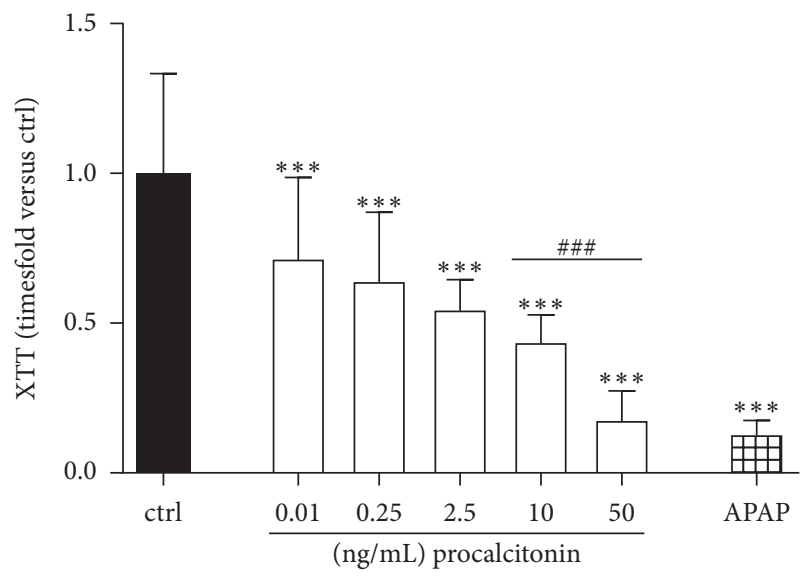

(c)

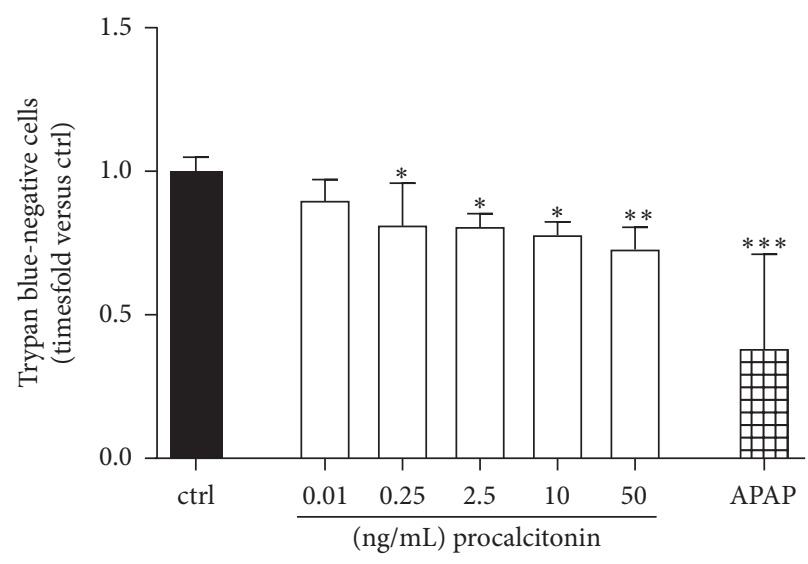

(b)

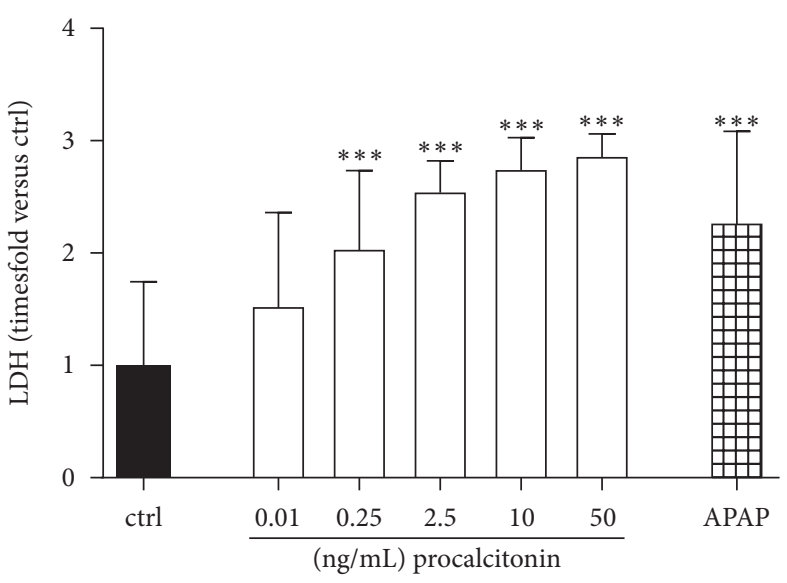

(d)

FIGURE 1: (a) Cell counts, (b) number of trypan blue-negative cells, (c) XTT metabolization, and (d) LDH release of HepG2/C3A cells following exposure to procalcitonin for $2 \times 72 \mathrm{~h}$ in concentrations as indicated. APAP acetaminophen $15.24 \mathrm{mM}$. $n=18-28$ biological replicates; ${ }^{*} P<0.05$ and ${ }^{* * *} P<0.001$ versus ctrl; $P<0.05, P<0.01$, and ${ }^{\# \# \#} P<0.001$ versus as indicated. Significance between concentrations is only indicated if differences between consecutive concentrations employed reach statistical significance.

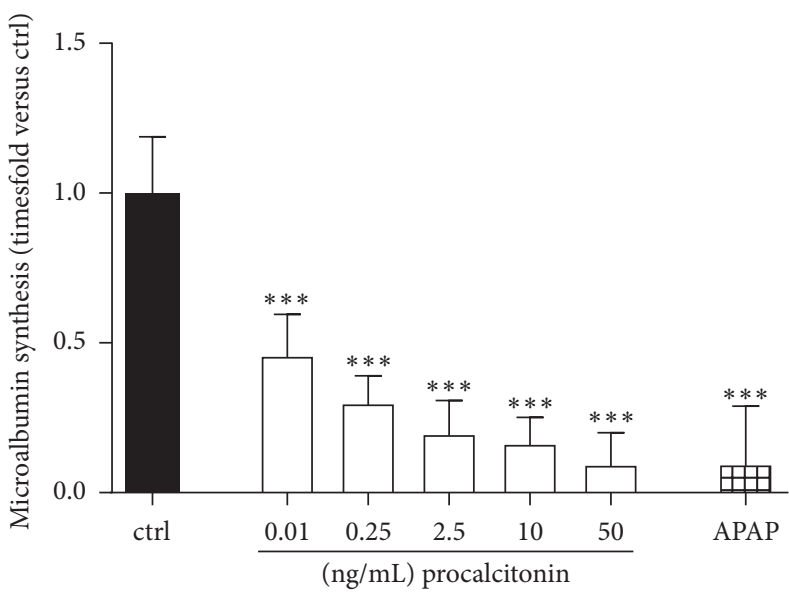

(a)

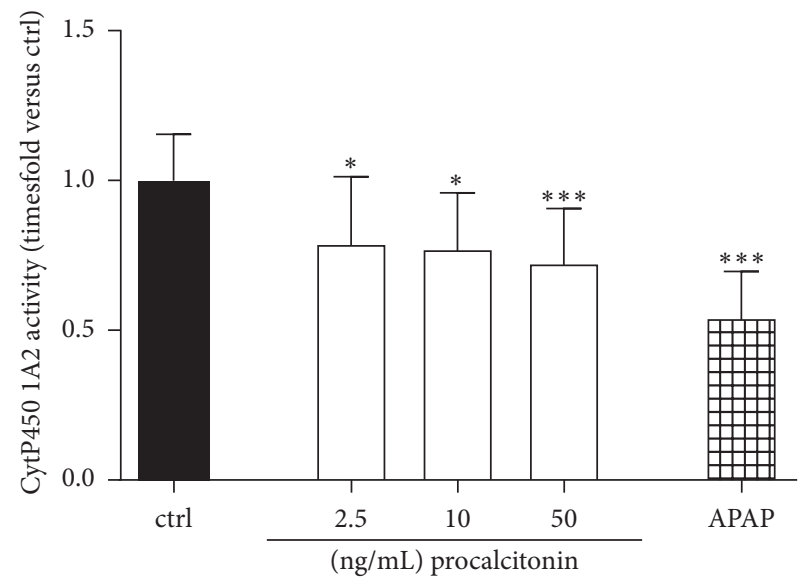

(b)

Figure 2: (a) Microalbumin synthesis ( $n=9-10$ biological replicates) and (b) cytochrome 1A2 detoxification $(n=36$ biological replicates) activity of HepG2/C3A cells following exposure to procalcitonin for $2 \times 72 \mathrm{~h}$ in concentrations as indicated. APAP acetaminophen $15.24 \mathrm{mM}$. $n=18-28 ;{ }^{*} P<0.05$ and ${ }^{* * *} P<0.001$ versus ctrl. Significance between concentrations is only indicated if differences between consecutive concentrations employed reach statistical significance. 


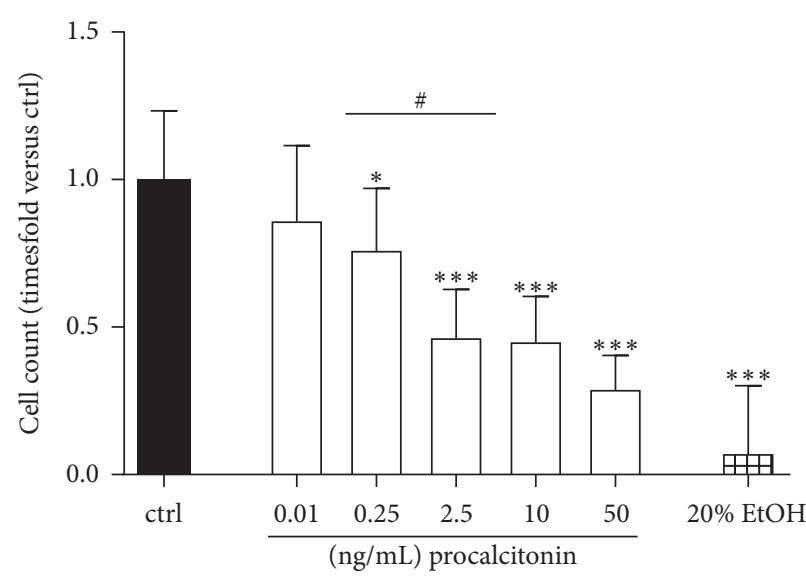

(a)

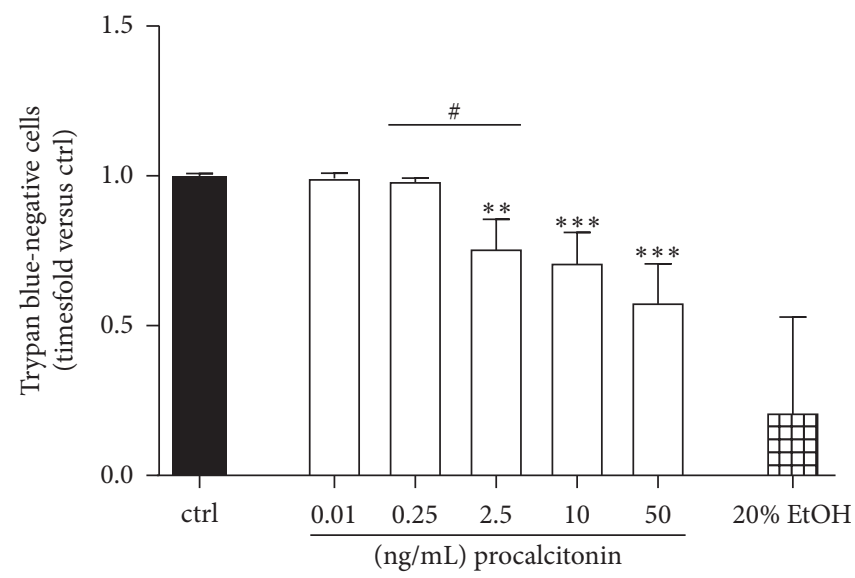

(b)

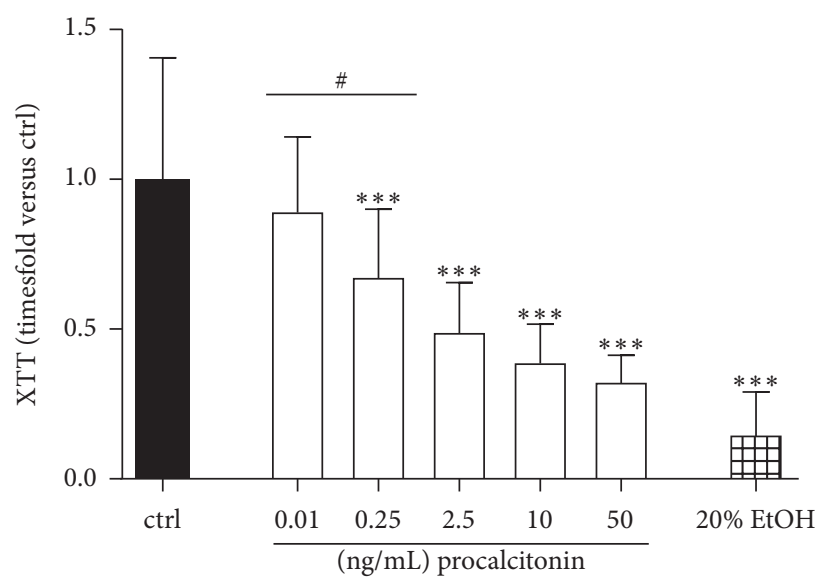

(c)

Figure 3: (a) Cell counts ( $n=9-18)$, (b) number of trypan blue-negative cells $(n=9-18)$, and (c) XTT metabolization $(n=18-36$ biological replicates) of L929 fibroblasts following exposure to procalcitonin for $2 \times 72 \mathrm{~h}$ in concentrations as indicated. EtOH ethanol $20 \% . n=18-28$ biological replicates; ${ }^{*} P<0.05,{ }^{* *} P<0.01$, and ${ }^{* * *} P<0.001$ versus $\mathrm{ctrl} ;{ }^{*} P<0.05$ versus as indicated. Significance between concentrations is only indicated if differences between consecutive concentrations employed reach statistical significance.

toxicology assay employing L929 fibroblasts. Here, procalcitonin beginning at $0.25 \mathrm{ng} / \mathrm{mL}$ affected cell proliferation indicated by lower cell counts following $2 \times 72 \mathrm{~h}$ of incubation $(0.76 \pm 0.21$-fold versus ctrl, $P<0.05$, Figure 3(a)). Beginning at similar concentrations, procalcitonin reduced cellular viability (reduction to $0.82 \pm 0.25$-fold trypan blue-negative cells compared to untreated control, $P<0.05$, Figure 3(b)). Again starting at low $0.25 \mathrm{ng} / \mathrm{mL}$, procalcitonin significantly reduced basal cell metabolism (to $0.68 \pm 0.23$-fold compared to ctrl, $P<0.001$, Figure 3(a)).

\section{Discussion}

Hepatic function is affected already during early stages of systemic infection. One of the first signs of hepatic dysfunction is an impairment of bile production. Under experimental conditions, a reduced canalicular bile secretion can be detected within minutes after initialization of endotoxemia [21, 22]. In this regard, previous studies identified that $10.9 \%$ of patients newly admitted to ICU exhibit bilirubin serum levels
$>34.2 \mu \mathrm{mol} / \mathrm{L}$ within $48 \mathrm{~h}$ of admission [23]. Histologic analysis of liver biopsies suggests rapid development of ubiquitous centrilobular necrosis and hepatocellular apoptosis during the course of sepsis [24]. These findings point towards a rapid onset of hepatocyte loss of integrity and functional impairment during the course of sepsis. Procalcitonin levels rise early during the course of systemic infection. While in healthy humans procalcitonin plasma concentration is mostly below $0.01 \mathrm{ng} / \mathrm{mL}$, consideration of sepsis is recommended if procalcitonin plasma levels exceed $0.5 \mathrm{ng} / \mathrm{mL}$ [25]. In the present study, we found that procalcitonin affects hepatocyte vitality, viability, and function already during lower concentrations, mostly at $0.25 \mathrm{ng} / \mathrm{mL}$. A dose dependent cell lysis was started even in very low concentrations of procalcitonin, displayed in high and increasing levels of lactate dehydrogenase in the cell culture supernatant. Procalcitonin similarly and mostly dose dependently affected all qualities of cellular function investigated such as proliferation, induction of cell death, metabolism, integrity, microalbumin synthesis, and detoxification capacity. Our results thus point towards procalcitonin 
as a potent and, importantly, early mediator of hepatic dysfunction during sepsis.

Chemokines and cytokines impair cellular functions and viability of primary hepatocytes and HepG2/C3A cells [2629]. Proinflammatory cytokines, for instance, are known to downregulate albumin synthesis [27], to cause a dysfunction of mitochondria [26], and to diminish function of some P450 cytochromes like CYP 1A2, CYP 2E1, and CYP 7A1 $[28,29]$. The panel of assays to study hepatocyte function and viability employed in this study has been previously patented for the early detection of patients endangered for the development of liver dysfunction during sepsis $[15,16]$. Further standardization was done by the employment of the panel for screening purposes during extracorporeal treatments and for an experimental model of liver dysfunction in Schistosoma infections [30, 31]. It utilizes the human hepatocellular carcinoma cell line HepG2/C3A, a well-characterized subclone of the hepatoma-derived HepG2 cell line often used for toxicological screening [32-34]. Biosynthesis capacity of plasma proteins and inflammatory mediators and the cell surface receptors expressed are highly similar to those of normal hepatocytes (see Sauer et al. for review, [16]). In addition, cellular ability for cytochrome P450 monooxidase-mediated detoxification and glucuronic- and sulfate-conjugation are also equal to those of hepatocytes. However, this in vitro testing system does not resemble the multitude of actors and processes hepatocytes within the liver tissue are exposed to during sepsis, which is a major limitation of this study. Further investigations are thus needed to analyze whether procalcitonin itself is a mediator of liver cell dysfunction during sepsis.

Interestingly, procalcitonin's ability to identify bacteraemia does not apply to patients suffering from liver failure. Hepatocyte necrosis correlates with high levels of procalcitonin irrespective of infection and authors concluded that the massive inflammation associated with hepatocyte necrosis may have triggered excess procalcitonin release [35]. During early stages of proinflammatory conditions, procalcitonin is secreted by cytokine-activated macrophages during their interaction with endothelial cells [7]. With persisting presence of proinflammatory mediators in the blood, further procalcitonin production and release is initiated in the parenchyma of a variety of organs, resulting in 10,000-100,000fold increase of procalcitonin plasma concentration [9]. The results of the present study now point towards procalcitonin itself to induce hepatocyte dysfunction and impairment of cellular integrity. This suggests procalcitonin as part of a vicious circle of sterile inflammation and liver cell necrosis. Future studies may thus address whether procalcitonin can be a potential target for the treatment of acute liver failure, the importance of inflammatory mediators, or whether the interplay of hepatocytes and procalcitonin is independent of infection.

Sepsis is associated with vascular barrier dysfunction, fluid extravasation, and rapid induction of microcirculatory disturbance. Our previous study identified procalcitonin to induce, within a few hours, endothelial cell dysfunction and endothelial cell death [14]. Liver failure occurs during late stages of sepsis-induced multiple organ dysfunction syndrome and hepatocytes were therefore exposed to procalcitonin for time periods of 6 days in the present study. Although times of incubation thus greatly differed, much higher concentrations of procalcitonin (i.e., $100 \mathrm{ng} / \mathrm{mL}$ for $6 \mathrm{~h}$ ) were needed to induce endothelial cell necrosis compared to only $0.25 \mathrm{ng} / \mathrm{mL}$ procalcitonin to induce hepatocyte necrosis in the present study. In the standardized cellular toxicology assays employing L929 fibroblasts, again higher procalcitonin concentrations, that is, $2.5 \mathrm{ng} / \mathrm{mL}$, were needed to induce cell death in a significant number of cells. Other studies employing renal mesangial cells reported similarly high concentrations of procalcitonin (i.e., $2.5-5 \mathrm{ng} / \mathrm{mL}$ ) to induce cell apoptosis [36], suggesting that hepatocytes may belong to more susceptible and other cell types such as endothelial or mesangial cells to a more insensitive extreme of a continuum of procalcitonin effects on cell function and viability. A limitation of this study is that we do not provide a mechanism of procalcitonin's actions on liver cell and fibroblast function that does apply to all the observations made. However in previous studies analysis of gene expression profiles in endothelial cells exposed to procalcitonin revealed regulation of genes involved in various cellular functions such as cell metabolism and inflammatory pathways [14]. Further studies are needed to investigate the underlying effects of how procalcitonin affects cellular integrity and whether neutralization of procalcitonin would modulate the occurrence of organ dysfunction and outcome during sepsis or other entities associated with increased procalcitonin plasma concentrations.

\section{Conclusion}

In conclusion, our experiments provide evidence for procalcitonin to directly impair function and viability of human hepatocytes and exert general cytotoxicity in vitro. The mechanisms for the hepatotoxicity of procalcitonin are unclear and need further investigations in suitable in vitro and in vivo models.

\section{Competing Interests}

All authors declare no actual or potential conflicts of interests.

\section{Authors' Contributions}

All authors were involved in the performance and analysis of the study.

\section{Acknowledgments}

The authors thank Heike Potschka for excellent technical assistance. This study relied solely on financial resources of the University of Rostock and the European Regional Development Fund (EFRE) and European Social Fund (ESF), Grant no. AU 09 046:ESF/IV-BM-B35-0005/12. 


\section{References}

[1] J. Jacobi, "Pathophysiology of sepsis," American Journal of Health-System Pharmacy, vol. 59, supplement 1, pp. S3-S8, 2002.

[2] J.-L. Vincent, D. R. Nelson, and M. D. Williams, "Is worsening multiple organ failure the cause of death in patients with severe sepsis?" Critical Care Medicine, vol. 39, no. 5, pp. 1050-1055, 2011.

[3] J. Bakker, R. Grover, A. McLuckie et al., "Administration of the nitric oxide synthase inhibitor NG-methyl- L-arginine hydrochloride (546C88) by intravenous infusion for up to 72 hours can promote the resolution of shock in patients with severe sepsis: results of a randomized, double-blind, placebo-controlled multicenter study (study no. 144-002)," Critical Care Medicine, vol. 32, no. 1, pp. 1-12, 2004.

[4] G. Szabo, L. Romics, and G. Frendl, "Liver in sepsis and systemic inflammatory response syndrome," Clinics in Liver Disease, vol. 6, no. 4, pp. 1045-1066, 2002.

[5] J.-F. Dhainaut, N. Marin, A. Mignon, and C. Vinsonneau, "Hepatic response to sepsis: interaction between coagulation and inflammatory processes," Critical Care Medicine, vol. 29, no. 7, pp. S42-S47, 2001.

[6] N. Nesseler, Y. Launey, C. Aninat, F. Morel, Y. Mallédant, and P. Seguin, "Clinical review: the liver in sepsis," Critical Care, vol. 16, no. 5, article 235, 2012.

[7] P. Linscheid, D. Seboek, D. J. Schaer, H. Zulewski, U. Keller, and B. Müller, "Expression and secretion of procalcitonin and calcitonin gene-related peptide by adherent monocytes and by macrophage-activated adipocytes," Critical Care Medicine, vol. 32, no. 8, pp. 1715-1721, 2004.

[8] M. Oberhoffer, I. Stonans, S. Russwurm et al., "Procalcitonin expression in human peripheral blood mononuclear cells and its modulation by lipopolysaccharides and sepsis-related cytokines in vitro," The Journal of Laboratory and Clinical Medicine, vol. 134, no. 1, pp. 49-55, 1999.

[9] S. Russwurm, I. Stonans, E. Stonane et al., "Procalcitonin and cgrp-1 mrna expression in various human tissues," Shock, vol. 16, pp. 109-112, 2001.

[10] N. G. Morgenthaler, J. Struck, Y. Chancerelle et al., "Production of procalcitonin (PCT) in non-thyroidal tissue after LPS injection," Hormone and Metabolic Research, vol. 35, no. 5, pp. $290-$ 295, 2003.

[11] E. S. Nylen, K. T. Whang, R. H. Snider Jr., P. M. Steinwald, J. C. White, and K. L. Becker, "Mortality is increased by procalcitonin and decreased by an antiserum reactive to procalcitonin in experimental sepsis," Critical Care Medicine, vol. 26, no. 6, pp. 1001-1006, 1998.

[12] K. E. Wagner, J. M. Martinez, S. D. Vath et al., "Early immunoneutralization of calcitonin precursors attenuates the adverse physiologic response to sepsis in pigs," Critical Care Medicine, vol. 30, no. 10, pp. 2313-2321, 2002.

[13] A. A. Dahaba and H. Metzler, "Procalcitonin's role in the sepsis cascade. Is procalcitonin a sepsis marker or mediator?" Minerva Anestesiologica, vol. 75, no. 7-8, pp. 447-452, 2009.

[14] N.-M. Wagner, C. Van Aken, A. Butschkau et al., "Procalcitonin impairs endothelial cell function and viability," Anesthesia \& Analgesia, 2016.

[15] M. Sauer, "The use of human hepatocytes to determine liver function and liver regeneration," PCT/EP 2007/001047; DE/ $2006102006005526,2007$.
[16] M. Sauer, C. Haubner, T. Mencke et al., "Impaired cell functions of hepatocytes incubated with plasma of septic patients," Inflammation Research, vol. 61, no. 6, pp. 609-616, 2012.

[17] D. A. Scudiero, R. H. Shoemaker, K. D. Paull et al., "Evaluation of a soluble tetrazolium/formazan assay for cell growth and drug sensitivity in culture using human and other tumor cell lines," Cancer Research, vol. 48, no. 17, pp. 4827-4833, 1988.

[18] K. Lorentz, R. Klauke, and E. Schmidt, "Recommendation for the determination of the catalytic concentration of lactate dehydrogenase at 37 degrees c. Standardization committee of the german society for clinical chemistry, enzyme working group of the german society for clinical chemistry," European Journal of Clinical Chemistry and Clinical Biochemistry, vol. 31, no. 12, pp. 897-899, 1993.

[19] N. Krasteva, T. Groth, F. Fey-Lamprecht, and G. Altankov, "The role of surface wettability on hepatocyte adhesive interactions and function," Journal of Biomaterials Science, Polymer Edition, vol. 12, no. 6, pp. 613-627, 2001.

[20] J. H. Kelly and N. L. Sussman, "A fluorescent cell-based assay for cytochrome P-450 isozyme 1A2 induction and inhibition," Journal of Biomolecular Screening, vol. 5, no. 4, pp. 249-253, 2000.

[21] U. Bolder, H.-T. Ton-Nu, C. D. Schteingart, E. Frick, and A. F. Hofmann, "Hepatocyte transport of bile acids and organic anions in endotoxemic rats: impaired uptake and secretion," Gastroenterology, vol. 112, no. 1, pp. 214-225, 1997.

[22] R. H. Moseley, "Sepsis and cholestasis," Clinics in Liver Disease, vol. 3, no. 3, pp. 465-475, 1999.

[23] L. Kramer, B. Jordan, W. Druml, P. Bauer, and P. G. H. Metnitz, "Incidence and prognosis of early hepatic dysfunction in critically ill patients-A Prospective Multicenter Study," Critical Care Medicine, vol. 35, no. 4, pp. 1099-1104, 2007.

[24] J. Koskinas, I. P. Gomatos, D. G. Tiniakos et al., "Liver histology in ICU patients dying from sepsis: a clinico-pathological study," World Journal of Gastroenterology, vol. 14, no. 9, pp. 1389-1393, 2008.

[25] M. Meisner, "Update on procalcitonin measurements," Annals of Laboratory Medicine, vol. 34, no. 4, pp. 263-273, 2014.

[26] T. Regueira, P. M. Lepper, S. Brandt et al., "Hypoxia inducible factor- $1 \alpha$ induction by tumour necrosis factor- $\alpha$, but not by tolllike receptor agonists, modulates cellular respiration in cultured human hepatocytes," Liver International, vol. 29, no. 10, pp. 1582-1592, 2009.

[27] M. A. El-Saadany, H. M. Rawel, J. Raila, M. S. El-Dashloty, and F. J. Schweigert, "Antioxidants modulate the IL-6 induced inhibition of negative acute-phase protein secretion in HepG2 cells," Cell Biochemistry and Function, vol. 26, no. 1, pp. 95-101, 2008.

[28] K. Nakai, H. Tanaka, K. Hanada et al., "Decreased expression of cytochromes P450 1A2, 2E1, and 3A4 and drug transporters $\mathrm{Na}^{+}$-taurocholate-cotransporting polypeptide, organic cation transporter 1 , and organic anion-transporting peptide- $C$ correlates with the progression of liver fibrosis in chronic hepatitis C patients," Drug Metabolism and Disposition, vol. 36, no. 9, pp. 1786-1793, 2008.

[29] T. Li, A. Jahan, and J. Y. L. Chiang, "Bile acids and cytokines inhibit the human cholesterol $7 \alpha$-hydroxylase gene via the JNK/ c-Jun pathway in human liver cells," Hepatology, vol. 43, no. 6, pp. 1202-1210, 2006.

[30] M. Sombetzki, N. Koslowski, S. Doss et al., "Biosensor for hepatocellular injury corresponds to experimental scoring of hepatosplenic schistosomiasis in mice," BioMed Research International, vol. 2016, Article ID 1567254, 7 pages, 2016. 
[31] M. Sauer, J. Altrichter, C. Haubner et al., "Bioartificial therapy of sepsis: changes of norepinephrine-dosage in patients and influence on dynamic and cell based liver tests during extracorporeal treatments," BioMed Research International, vol. 2016, Article ID 7056492, 11 pages, 2016.

[32] J. H. Kelly and G. J. Darlington, "Modulation of the liver specific phenotype in the human hepatoblastoma line Hep G2," In Vitro Cellular \& Developmental Biology, vol. 25, no. 2, pp. 217-222, 1989.

[33] M. Modrianský, J. Ulrichová, P. Bachleda et al., "Human hepatocyte - a model for toxicological studies. Functional and biochemical characterization," General Physiology and Biophysics, vol. 19, no. 2, pp. 223-235, 2000.

[34] P. F. Dehn, C. M. White, D. E. Conners, G. Shipkey, and T. A. Cumbo, "Characterization of the human hepatocellular carcinoma (HEPG2) cell line as an in vitro model for cadmium toxicity studies," In Vitro Cellular and Developmental Biology Animal, vol. 40, no. 5-6, pp. 172-182, 2004.

[35] J. A. Rule, L. S. Hynan, N. Attar et al., "Procalcitonin identifies cell injury, not bacterial infection, in acute liver failure," PLoS ONE, vol. 10, no. 9, Article ID e0138566, 2015.

[36] M. Araujo, S. Q. Doi, C. E. Palant, E. S. Nylen, and K. L. Becker, "Procalcitonin induced cytotoxicity and apoptosis in mesangial cells: implications for septic renal injury," Inflammation Research, vol. 62, no. 10, pp. 887-894, 2013. 


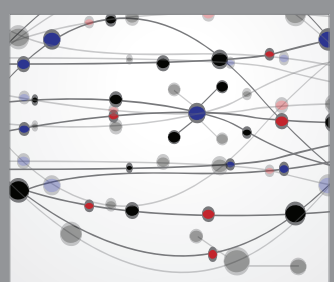

The Scientific World Journal
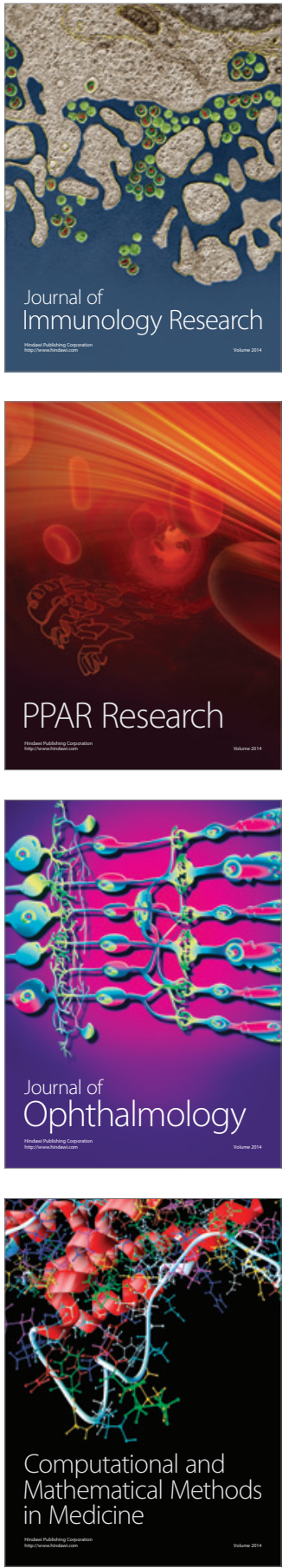

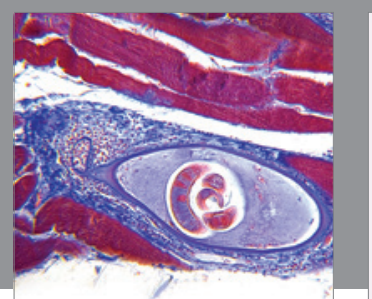

Gastroenterology Research and Practice
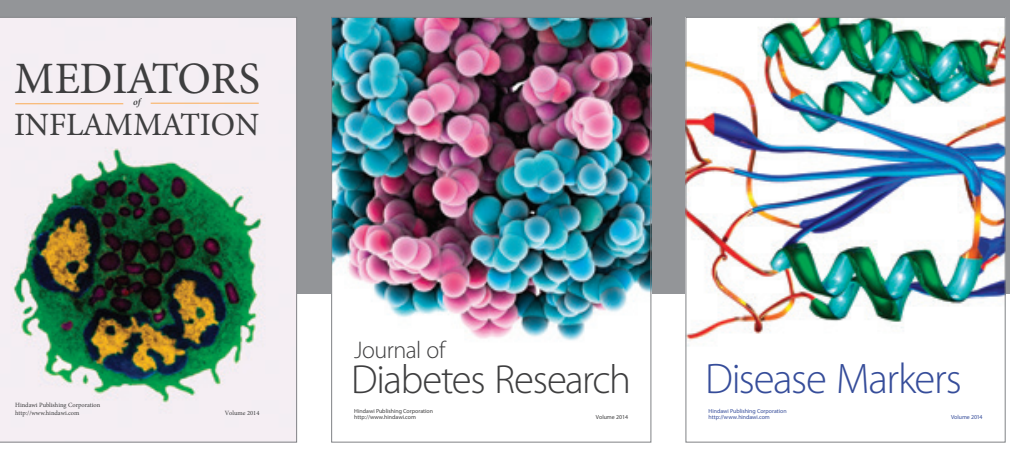

Disease Markers

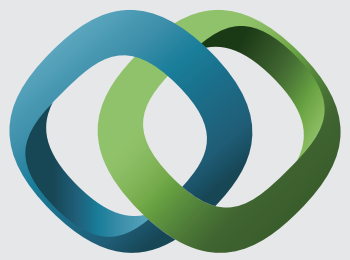

\section{Hindawi}

Submit your manuscripts at

https://www.hindawi.com
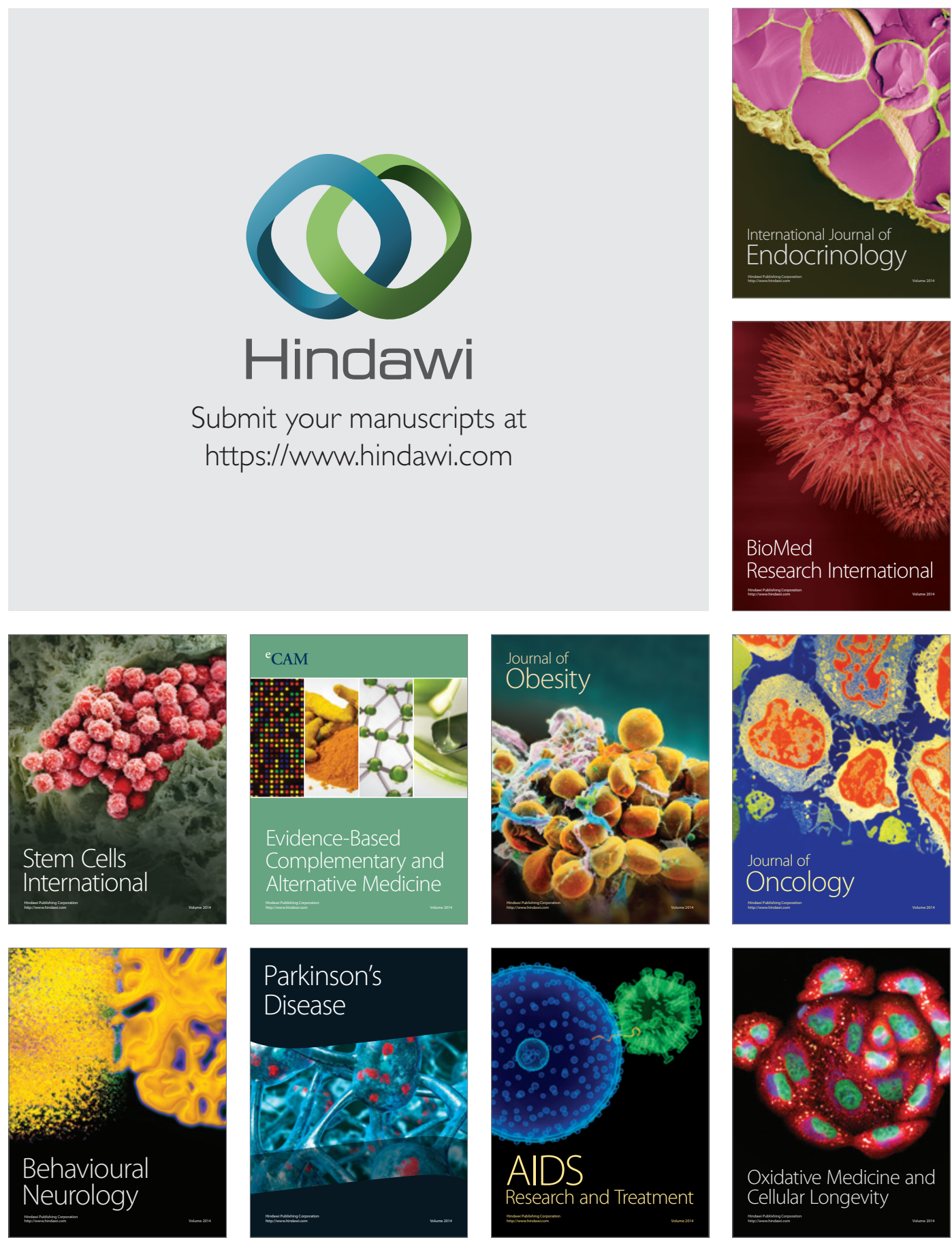